\title{
Linguistic Foundations of Heritage Language Development from the Perspective of Romance Languages in Germany
}

\section{Cristina Flores, Tanja Kupisch, and Esther Rinke}

\section{Contents}

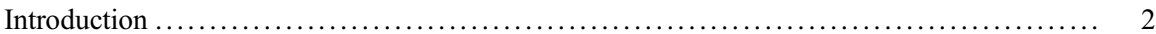

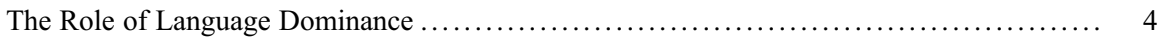

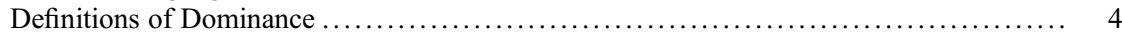

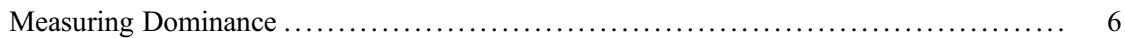

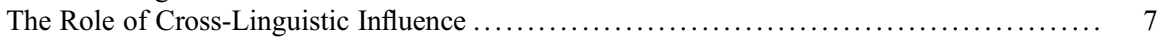

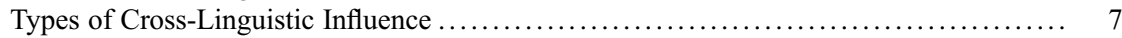

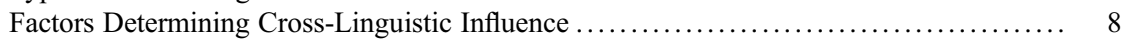

Cross-linguistic Influence in Adult Heritage Speakers ............................ 9

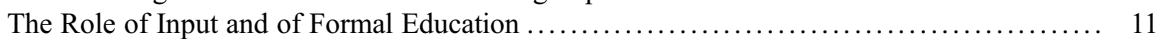

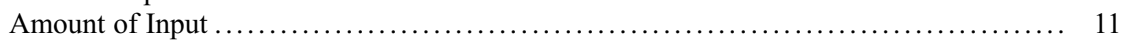

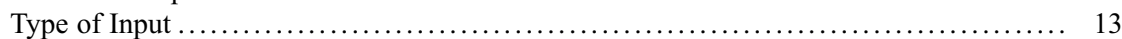

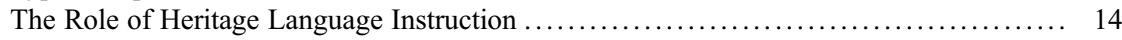

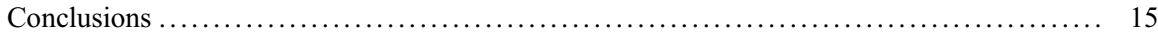

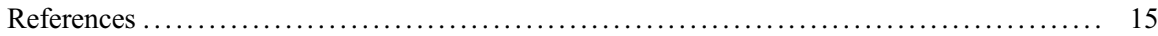

\begin{abstract}
This paper discusses the role of different factors determining the linguistic competence of heritage speakers (HSs) based on examples from speakers who speak a Romance language (French, Italian, Portuguese, or Spanish) as heritage
\end{abstract}

\section{Flores $(\bowtie)$}

Departmento de Estudos Germanísticos e Eslavos (DEGE), Universidade do Minho, Braga, Portugal

e-mail: cflores@ilch.uminho.pt

\section{T. Kupisch}

Universität Konstanz and the Arctic University of Norway, Constance, Germany

e-mail: tanja.kupisch@uni-konstanz.de

\section{E. Rinke}

Goethe-Universität Frankfurt, Frankfurt, Germany

e-mail: Esther.Rinke@em.uni-frankfurt.de 
language (HL) and German as the environmental language. Since the relative amount of contact with the HL and the environmental language may vary during the acquisition process, the role of language dominance (in terms of relative language proficiency) is of particular interest for HL development. In addition to dominance (and related to it), cross-linguistic influence (CLI) may have an influence on the outcome of HL acquisition. Finally, quality and quantity of input also determine HL acquisition and will be discussed in connection with heritage language education.

\section{Keywords}

Romance heritage speakers $\bullet$ Language dominance $\bullet$ Cross-linguistic $\bullet$ The role of input

\section{Introduction}

Germany's status as popular migration destination started a decade after the end of World War II, when manpower was needed during the so-called German "economic miracle." In order to make up for the need for low-skilled work in the industrial sector, the West German government signed several bilateral recruitment agreements mainly with Mediterranean countries, the first being Italy in 1955. The agreement with Spain was signed in 1960 and with Portugal in 1964. For the underprivileged social classes in Italy, Portugal, and Spain, immigration to Germany was a way to escape from extremely poor living conditions, from dictatorship regimes in the case of Portugal and Spain and from the colonial war between Portugal and its African colonies. As a result, almost 170,000 Portuguese, 600,000 Spanish and Italian laborers were employed in German factories between 1955 and 1975. Immigration from France also existed, but it has always been somewhat different. People from France also changed their country of residence to improve working or living conditions, but living standards were already very high in France compared to the other Romance language-speaking countries.

The term given by the German government to describe the first generation of immigrants, Gastarbeiter ("guest workers"), reveals a labor recruitment policy based on the idea of a limited period of migration and the subsequent return of the migrants to their homelands. In the late seventies, this return was encouraged by the German government with advantageous return conditions, which, however, only a small part of the migrants reclaimed. Since then, there has been a continued process of migration and remigration to/from Germany. With the recent economic crisis, southern European immigration to Germany increased once again, attracting also skilled employees and academics. Consequently, several generations of Portuguese, Spanish, and Italian migrants are living in Germany nowadays: from the third generation - in many cases residents with German nationality whose grandparents immigrated in the sixties - to first-generation migrants, who immigrated in the last decade, often with children who had been born abroad. Immigration to Germany 
from these southern European countries, as well as from France, implies political, geographical, and cultural closeness between home and host country that is mostly absent in immigration flows in non-European contexts, as the US, for instance. This proximity and the multilingual policy that constitutes one basic principle of EU politics may foster an explicit endeavor to maintain the language of origin that is perhaps less present in non-EU migration contexts.

This paper focuses on the linguistic foundations of heritage language (HL) development from the perspective of Romance languages in Germany. More precisely, it addresses the linguistic development and competence of second (and third) generation of migrants, i.e., heritage speakers (HSs) with one language (French, Italian, Portuguese, or Spanish) acquired as HL within the family context and the other language (German) as the environmental language. Many HSs are simultaneous bilinguals in the sense that they acquired both languages from birth (2L1). In other cases, contact with the environmental language starts later in early childhood, i.e., after the age of three years. These speakers may be best characterized as early L2 acquirers (eL2) of German. Typically, when the HL-speaking child enters the German school system (around the age of six years) the amount of exposure to the environmental language increases, with the effect that German becomes the preferred language in everyday life. Whether this situation leads to a "dominance shift" - where dominance is understood in terms of relative language proficiency depends at least partially on the amount of contact with the HL. Section "The Role of Language Dominance" is concerned with the relations between language dominance, input and use, language preference as well as their consequences for HL development.

Another topic that will be discussed is potential cross-linguistic influence (CLI). Three types of CLI have been discussed in the literature: (a) acceleration, (b) delay, and (c) transfer. The first two refer to differences concerning the rate of acquisition with respect to monolinguals, the latter to "incorporation of a grammatical property into one language from the other" (Paradis and Genesee 1996: 3). Only transfer implies changes to the grammatical structure of a language and would therefore be the most plausible explanation for differences between the linguistic knowledge of adult bilingual and monolingual speakers. However, as will be shown in section "The Role of Cross-Linguistic Influence", the occurrence of transfer in 2L1 and eL2 bilingual speakers is much debated and it is unclear whether transfer in the sense defined above indeed occurs and under which conditions.

In addition to dominance and transfer, the bilingual speakers' quantitative and qualitative input has received a great deal of attention, specifically, the question whether reduced input will result in a grammar that differs from that of a monolingual speaker. These questions are discussed in section "The Role of Input and of Formal Education" along with the role of HL education.

Although this chapter is dedicated to Romance-German bilingualism in Germany, where a lot of research has been carried out during the past 30 years, it is obvious, given space limits, that the discussion cannot be exhaustive. At the same time, also other groundbreaking studies that have focused on HLs outside of Germany will be mentioned. 


\section{The Role of Language Dominance}

\section{Definitions of Dominance}

It seems fitting in a section on language dominance to start by defining the term. There are (at least) three different types of definitions: (i) proficiency-based, (ii) usage-based, and (iii) context-based. The three are related in ways to be specified further below. Herein, the proficiency-based definition will be adopted, since it is the most-widely used one. The notion of language dominance has been more intensively researched with respect to simultaneous bilinguals rather than HSs in a more general sense possibly because it is often taken for granted that HSs are initially dominant in their HL and, after school entry, become dominant in the majority language. Generally, the dominant language is referred to as the "stronger" and the language developing more slowly as the "weaker" language (Schlyter 1994).

In research on both child and adult bilinguals, the proficiency- or competencebased definition is fairly common. For bilingual children, for example, the dominant language has been described as the language "in which the bilingual is informally considered to be most proficient" (Genesee et al. 1995, among others). Dimensions relating to linguistic proficiency or competence include language production and processing, more specifically fluency, lexical diversity, morphosyntactic knowledge, length of utterances, parsing speed, and accuracy (Birdsong 2014: 3-4).

As an alternative to the proficiency dimension, dominance is sometimes defined in terms of the language that is used relatively more frequently, actively or passively. Frequency of use is equivalent to input in a broad sense, which can be measured in quantitative or in qualitative terms (cf. section "Conclusions"). Measurements are typically based on current language use, but there have also been proposals that take a longitudinal perspective (cumulative input, cf. Unsworth 2013). Usage-based dominance often correlates with proficiency-based dominance. For example, in a recent study, Lloyd-Smith et al. (2016) have calculated a usage-based dominance score for German-Turkish bilinguals, based on factors such as Turkish use with family members and friends, at home and at work, frequency and length of trips to Turkey and the modes of Turkish use (reading, writing, speaking, listening). The resulting "Turkish Use Score" mirrored how native-like their pronunciation was perceived to be. Speakers who used Turkish more sounded comparatively more native-like when speaking Turkish. Conversely, however, the amount of Turkish use was unrelated to how native-like the bilinguals sounded in German. In other words, using Turkish more often did not affect the speakers' German accent negatively, although it did affect their Turkish accent positively.

A third possibility is to define language dominance in terms of the language of the environment. Not surprisingly, many early bilinguals will end up being more proficient in the language of their national environment, i.e., the language they will hear and use more often. Kupisch and colleagues have shown this in several studies by comparing simultaneous bilinguals with the same language combination in different countries, i.e., German-Italian speakers in Germany vs. German-Italian speakers in Italy. While the bilinguals performed monolingual-like in the majority 
language of their environment, there was a lot of variation in their performance in the minority language. This was the case for various phenomena including gender assignment and agreement (Bianchi 2013; Stöhr et al. 2012), adjective placement (Kupisch 2014), article use (Kupisch 2012), and perceived foreign accent (Kupisch et al. 2014). However, early bilinguals who change their country of residence will not necessarily become dominant in the language of their new environment. Kupisch and colleagues studied two groups of German-French bilinguals. One group had been born and raised in Germany and lived there as adults, while the other group had been born and raised in France but had moved to Germany as adults. It turned out that the speakers were more proficient in the language of their childhood environment. In other words, the German-French bilinguals from France were more proficient in French, even though some of them had been living in Germany for more than ten years. This was particularly evident when their accents in German and French were judged by native speakers of the respective languages (Kupisch and van de Weijer 2016).

The strong effect of the environmental language is also witnessed by some welldocumented cases that report dominance shifts in bilingual children who changed their countries of residence when their parents moved abroad (Berman 1979; Leopold 1949). Flores (2015a) describes a dominance shift from German toward Portuguese within 13 months in Ana, a Portuguese-German bilingual child who grew up in Germany and moved to Portugal at the age of nine years. Five months after moving to Portugal, the girl showed first word retrieval difficulties and discursive inappropriate omissions. Thirteen months later even syntactic and morphological deficits were observed in the language that was no longer spoken in her daily life.

Although the majority language of the national environment often ends up being dominant, some bilingual children are more proficient in the HL during their early years. This is especially typical for children from homes where only the minority language is spoken, but it may also be the case for simultaneous bilinguals who hear two different languages at home, e.g., when they stay at home with their mothers and their mothers speak the minority language. For example, the four children in Kupisch (2007) were all exposed to both Italian and German at home, but between the ages of two and three they had different dominance profiles: two children were balanced, one was German-dominant and one was Italian-dominant.

The validity of the term language dominance has been previously questioned, for it seems to suggest that production and processing of one language, namely the "weaker" one, will always be "governed" or "determined" by the stronger language. Moreover, dominance is often measured with respect to a monolingual norm, i.e., the rules of a language as found in a prescriptive grammar, although many speakers of a language do not perform according to this norm, not even monolinguals (Dabrowska 2012). Even though this criticism is valid, determining language dominance can be useful, as it may be an explanation for the occurrence or directionality of CLI (see below), or it may explain why a child lags behind monolinguals in language development, which can be important in a clinical context. 


\section{Measuring Dominance}

In the literature on child bilinguals various criteria have been adopted to measure dominance. The most frequently used measure is the mean length of utterances (MLU), which can be based on words (MLUw) or on morphemes (MLUm). Another frequently used measurement is the portion of utterances in the target-language (i.e., the language of the interlocutor) compared to mixed utterances (i.e., utterances containing words from both languages) or utterances in the other (nontarget) language. Other criteria include the total number of utterances, lexical diversity (often based on nouns or verbs), the number of multilingual words, and the number of hesitations. These measurements are based on the assumption that in the dominant language, a child uses longer utterances, sticks to the language of the interlocutor, speaks more, has a larger vocabulary, and hesitates less.

The chosen measures will depend on the bilingual speaker's age, the language combination and how much time the researcher has. For example, an MLU is a good measure until age 3, but after that children's utterances can already be fairly long and there is not much increase so that the two languages will not differ. For children below age 2 or even below age 1;6, MLU and lexical diversity may not be ideal measures because the child is still in the one-word stage, there is little to no morphology (depending on the language) and the words cannot always be categorized in terms of language. For such young children, criteria based on phonological measures are more useful, e.g., the consonant inventory or the complexity of syllables (Ingram 2002). For adults, it is typical to use cloze tests, vocabulary tasks or self-assessments, which are less time-consuming both when testing and during the analysis.

Since not all languages are made equal, it is further necessary to take into account the nature of the languages being compared. For example, when comparing MLU in a language where compounding is common (e.g. German) and a language where compounding is uncommon (e.g. French), one might think about counting the components of German compounds as separate words. Since a German compound might translate into three words in French (Ge. Waschmaschine vs. Fr. machine à laver "washing machine"), the risk is that the German MLU turns out lower for reasons unrelated to MLU. Similar problems arise when comparing a language with null subjects (e.g., Italian) to a language with overt subjects (e.g., German) or when comparing article languages (e.g., the Romance languages) to article-less languages (e.g., Russian), because one language provides for more opportunities to produce words. Generally, a word-based MLU is preferable when comparing languages with rich morphology (e.g., Italian) to languages with less morphology (e.g., English), although it may not be possible to adjust measures in each individual case.

The ratio of mixed utterances has often been used as a dominance measure, especially in combination with MLU, the idea being that in their weaker language, children have to resort to their respective other language more often because of structural or lexical needs. The expectation is that mixing is unidirectional from the dominant to the weaker language. Children may even "borrow" functional structure from one language into the other language (Bernardini and Schlyter 2004; 
Gawlitzek-Maiwald and Tracy 1996) Bernardini and Schlyter 2004). Unidirectional transfer has also been demonstrated in the context of bilectal acquisition. Kupisch and Klaschik (forthcoming) studied gender marking in Standard Italian and Venetian children who grew in the Veneto area in Italy. These children were more likely to use Italian words in Venetian rather than the other way round, and the pattern was more evident in children with less dialect exposure compared to children with more dialect exposure. On the other hand, there are cases where mixing is not unidirectional from stronger to weaker language (see Cantone 2007; Yip and Matthews 2006).

Taken together, younger children may be initially dominant in their HL or in the language of the national community. Adult bilinguals tend to be dominant in the language of the environment. In the section "The Role of Cross-Linguistic Influence" we discuss whether language dominance has an influence on CLI.

\section{The Role of Cross-Linguistic Influence}

\section{Types of Cross-Linguistic Influence}

CLI has been much debated in the 1970s and 1980s with respect to the question whether the two languages of the bilingual speaker develop independently or dependently from each other. In this context, Volterra and Taeschner (1978) have proposed a three-phase model of bilingual language development: in the first phase, the two language systems are fused; in the second phase, children have separate lexicons but one syntax for both languages. In the third phase, the linguistic systems are separated. One central argument for the assumption of an initially fused linguistic system was that children combine lexical elements from both of their languages. Genesee (1989) and Meisel (1989) independently argued against this point of view. They emphasized that combinations of elements from both languages are also found in adult speech and are typically referred to as code-switching. Code-switching is a systematic process. Neither in adult nor in child bilinguals is it arbitrary. Paradis and Genesee (1996) proposed three possible manifestations of CLI: (a) acceleration, (b) delay, and (c) transfer, however, without finding any evidence of CLI in their own study.

Gawlitzek-Maiwald and Tracy (1996) defend that in cases where one language develops more slowly than the other, the child may compensate for the nonavailability of certain linguistic means in the slower language by "importing" structures from the more advanced language (Bilingual Bootstrapping Hypothesis). According to the authors, Bilingual Bootstrapping means that "... something that has been acquired in language A fulfills a booster function for language B. In a weaker version, we would expect at least a temporary pooling of resources" (GawlitzekMaiwald and Tracy 1996: 903). They observed that a German-English bilingual child, who is dominant in German, sometimes produces mixed utterances containing a German IP and an English VP. According to the authors, the availability of the German structure has a booster function for the syntactic development of the English grammar. Kupisch (2007) studied four German-Italian bilingual children, showing 
that three of them acquired articles faster compared to monolingual German children. Since Italian articles are generally acquired earlier by monolingual Italian children compared to monolingual German children, it is plausible to assume that these children profited from their exposure to Italian when acquiring German articles.

Müller and Hulk (2001) studied several bilingual children with a Germanic and a Romance language (Dutch-French, German-French, German-Italian). In their Romance languages, the children acquired clitic object pronouns somewhat more slowly compared to monolingual children, i.e., showing a delay.

In general, studies on child bilingualism have found more evidence for delay or acceleration than for transfer in the sense of Paradis and Genesee (1996). However, studies on adult bilinguals tend to attribute differences between monolingual and bilingual speakers to "transfer". This will be discussed in the section "Cross-linguistic Influence in Adult Heritage Speakers".

\section{Factors Determining Cross-Linguistic Influence}

Müller and Hulk (2001) proposed that CLI depends on two factors: first, the phenomenon under consideration is situated at the interface of syntax and pragmatics and second, language A has an ambiguous structure, i.e., a structure which can be interpreted in two possible ways, and language B offers evidence for one of these possible interpretations (partial structural overlap). In their data, influence into the Romance language occurred even if the Romance language was temporarily dominant, suggesting that language dominance does not play a prominent role. However, the children in their dataset were rather balanced when compared to other, more extreme cases of language imbalance, e.g., those discussed by Schlyter (1994).

Many researchers who were primarily interested in the conditions under which CLI takes place have considered language dominance as a potential factor that determines the direction of CLI. Yip and Matthews $(2000,2006)$ show that their Cantonese-English bilingual participants (aged 1-4 years) were dominant in Cantonese and CLI from Cantonese to English was visible in many areas of grammar, whereas influence of English on Cantonese was much more difficult to demonstrate (Yip and Matthews 2000). Serratrice et al. (2009) investigated Italian-English school age children (ages 6-11) with regard to their use of determiners in Italian and English, comparing bilinguals in Italy with bilinguals in the UK. The bilinguals in Italy performed comparatively more target-like in Italian, while the bilinguals in England performed comparatively more target-like in English. Note that the authors took the language of the community to be dominant rather than measuring proficiency independently. Argyri and Sorace (2007) investigated eight-year-old EnglishGreek school-age children, comparing word-order patterns and pronoun use. CLI was primarily constrained by surface overlap between the two languages, i.e., structural similarities, which may be misinterpreted by the child. In this study, CLI 
was also constrained by language dominance, since it was manifested only in English-dominant children.

An interaction of several factors was also argued for by Kupisch (2007). As mentioned above, the author studied CLI in four German-Italian bilingual children who all grew up in Germany but differed in their dominance profiles. Positive CLI from Italian to German was found in the Italian-dominant child as well as in the balanced bilingual children, but not in the German-dominant child. The author argued that a positive influence from one language to another does not manifest itself if the potentially influencing language is the weaker language. These latter studies, as well as those demonstrating an impact of the language of the environment (see above), attribute an important role to the dominant language.

Dominance also plays a prominent role for CLI in the phonological development of bilingual children. However, other factors come into play as well. According to Kehoe et al. (2001), markedness and the relative complexity of phonological phenomena are relevant. The authors found that German-Spanish bilingual children showed a delay in their acquisition of voice onset time (VOT). They attributed this delay to the fact that both German and Spanish contain marked VOT values. Markedness was also relevant for CLI in the acquisition of more complex prosodic structures, such as syllables. Lleó (2002) argues for a delay in the bilingual acquisition of structures "in the sense that unmarked structures last longer and more complex structures are acquired later" (Lleó 2002: 308). This delay concerns, for instance, the target-like production of lexical items containing unfooted syllables (iambs and amphibrachic trisyllables) in the Spanish of Spanish-German bilingual children. However, the author also shows that the bilingual children overcome this delay within a few months and "about the end of the second year of age, bilinguals reach the same level of acquisition as that of monolinguals." (Lleo 2002: 308).

Acceleration was found, e.g., with respect to coda production in the Spanish of German-Spanish bilinguals. Specifically, the high frequency of codas in German had a positive influence on the acquisition of Spanish (Lleó et al. 2003). In addition to markedness and frequency, the probability of CLI seems to depend on the phonological phenomenon. It has been shown in several studies that CLI is more likely to occur with consonants than with vowels, which might be due to the complexity of the consonant system in comparison to vowels (Kehoe et al. 2004; Lleó and Rakow 2005, but see Kehoe 2002 for a delay in the acquisition of vowel length).

In summary, potential sources of cross-linguistic influence include at least language dominance, structural factors (overlap, ambiguity, complexity/markedness), and frequency of occurrence.

\section{Cross-linguistic Influence in Adult Heritage Speakers}

The debate of CLI is not restricted to developing child bilinguals but is also relevant for differences between adult monolingual and bilingual speakers. Montrul (2010) claims that transfer from the dominant environmental language to the HL is typical for HSs, and it is something that HSs have in common with adult second language 
(L2) learners. The author argues that "Because heritage language acquisition takes place in a bilingual environment, as heritage learners develop command of the majority language, they also make transfer errors.” (Montrul 2010: 12)

One example for transfer is provided by Montrul and Ionin (2010) with respect to the use of Spanish articles by English-Spanish heritage bilinguals. The authors demonstrate that Spanish HSs show a preference for the specific interpretation of ambiguous articles whereas monolingual speakers of Spanish prefer the generic reading. The heritage bilinguals also accept bare plural nouns as generic subjects, although these are ungrammatical in Spanish (En. Tigers eat meat. vs. Sp. *Tigres comen carne.). Although the authors explicitly talk about "transfer from the dominant language at the level of semantics" (Montrul and Ionin 2010: 450), they do not clarify what exactly is transferred from one language to the other and what exactly they mean by transfer (cf. the definition by Paradis and Genesee (1996) introduced above).

Kupisch (2012) shows the same effect with respect to German-Italian bilingual speakers, i.e., with a typologically similar language pair. However, in her study, transfer depends on language dominance: German-dominant speakers show CLI in their use of Italian articles, but Italian dominant HSs don't.

Dominance was also an important factor in Bianchi's (2013) study on gender assignment and agreement in Italian-German bilinguals. This study showed that only the German-dominant group of bilinguals differed substantially from the Italian monolinguals whereas the Italian-dominant group did not. With respect to CLI, the study further revealed that not all differences between the bilingual and the monolingual speakers could be explained on the basis of influence from German. The author observes that in some cases, "both groups of speakers performed better for words that have different genders in the two languages. In other words, languageinternal factors such as the predictability of gender based on noun endings play a major role in successful gender assignment. Only when the noun ending fails to provide a clue for gender assignment do speakers potentially turn to the other language." (Bianchi 2013: 553). Thus, not all differences between adult monolingual and bilingual speakers can automatically be attributed to the influence of the other language. Similarly, with respect to the knowledge of clitics by German-Portuguese heritage bilinguals living in Germany, Rinke and Flores (2014) argue that not all differences between monolingual and HSs of European Portuguese (EP) can be captured in terms of transfer from German. European Portuguese does not allow strong pronouns in object position, whereas German does. Although the HSs accepted some strong pronouns as accusative objects in European Portuguese (EP), they accept strong dative pronouns more easily. This dative-accusative asymmetry is not found in German but it is also observed in the results of the monolingual control speakers of EP. Interestingly, diachronic studies too show that dative pronouns are typically affected by diachronic change before accusative pronouns (Fischer and Rinke 2013). Thus, with respect to the use of strong pronominal objects, the HSs seem to follow universal linguistic tendencies, extending variation that also exists in the monolingual speech. 
Similarly, Schmitz et al. (2016) found no evidence of CLI in their study on the realization of subjects in first- and second-generation Italian-German and SpanishGerman immigrants and monolingual Italian and Spanish control groups. Although there are some differences between the bilingual and the monolingual groups, the authors conclude that subject use in all groups is determined by linguistic features (grammatical person) and not by speaker group.

Finally, linguistic properties that are acquired late in childhood are particularly challenging for HSs (in contrast to early structures, see Santos and Flores 2016). This has been shown by Kupisch (2012), for instance, with respect to article use in heritage Italian. Flores et al. (2016) too conclude with respect to the acquisition of mood in heritage Portuguese that "In HL development, these late-stabilized properties are precisely the most effected by reduced input. In the case of these structures, it is probably particularly relevant that this exposure does not decrease before the moment in which the relevant acquisition is expected to occur." (Flores et al. 2016: 31). The role of input is discussed in the following sections.

\section{The Role of Input and of Formal Education}

\section{Amount of Input}

One major outcome of the growing body of research in the field of HL development is the high degree of variation that characterizes HSs' proficiency. Among other factors, this variable performance of heritage bilinguals may be due to differences in exposure to the minority language, i.e., variation in the quantity and quality of contact with the HL, not only in childhood but also over the lifespan. In fact, the amount of exposure to the HL during the various phases of development may range from very restricted to very frequent, depending on the familiar and social constellation the HL-speaking child grows up in.

Several variables determine the amount of input that a speaker receives during childhood, e.g., the languages spoken by the caretakers, the number of siblings, the number of native speakers, and the nature and number of activities performed in this language (see Unsworth 2013, 2015, for an overview, and Bohman et al. 2010, for a case and cross-sectional study).

An influential variable is the language spoken at home. Bilingual parents may choose to use predominantly the HL in home communication or both, the HL and the majority language, or even a third language in the case of mixed marriages. As has been demonstrated by Flores et al. (2016), this choice often depends on the migration background of the parents. First-generation parents who migrate as adults (and often achieve low proficiency in the majority language) tend to stick to the language of origin, while second-generation/bilingual parents use both languages when interacting with their children. In the former case, the HL child is primarily exposed to the $\mathrm{HL}$ in his/her early years and starts to acquire the majority language as an early L2, mostly when entering kindergarten (or school), thus, representing a case of 
successive language acquisition. In the latter case, the child grows up with simultaneous exposure to the $\mathrm{HL}$ and the majority language, which also means more limited contact with the HL from early on. Various studies focusing on the role of parental input have shown that the language constellation at home influences the development of the HL (Gathercole and Thomas 2009; Rodina and Westergaard 2015; Suchtelen 2014; Thomas et al. 2014; Unsworth 2013). Rodina and Westergaard (2015), for instance, show that in the acquisition of gender Norwegian-Russian bilingual children from households where the two parents speak the HL, Russian, outperform bilingual children from mixed households, who have less exposure to Russian. Flores et al. (2016) reach similar conclusions regarding the acquisition of the subjunctive mood in complement clauses by HL children of EP in Germany. The children who grew up speaking predominantly Portuguese at home used the subjunctive mood significantly earlier than children who were exposed to Portuguese and German from birth.

A question that is intrinsically linked to this observation is whether the developmental delay caused by reduced input in early childhood is overcome in adulthood. Opinions and results diverge with respect to this question. Many scholars argue that HL children with less input in early years catch up with dominant HL children in older years, so that early input differences are no longer visible in the performance of older children, adolescents, or adults (e.g., Gathercole and Thomas 2009). This is the case of the EP HL children analyzed by Flores et al. (2016), who show that the differences observed in the rate of acquisition of the subjunctive mood by children with different parental input are no longer visible in adolescence (See also Flores and Barbosa 2014, for similar conclusions related with the acquisition of clitic placement in EP). Similarly, the studies carried out by Kupisch $(2012,2014)$ on adult HSs of French who grew up with simultaneous exposure to the HL and German demonstrate that these speakers perform native-like in several domains of morphosyntax, thus showing no effects of reduced exposure to the HL in the long run. However, unlike in the other studies, these speakers were also exposed to their HL throughout their school years with the HL as the medium of instruction.

Not all studies come to such positive findings. Suchtelen (2014), for instance, who analyzed the dative constructions in adult HSs of Spanish in the Netherlands observes significant interindividual differences, which are related to their history of contact with Spanish during their childhood. Those speakers who grew up with only one Spanishspeaking parent or who had less contact with the HL in childhood do not show the same knowledge of dative constructions as HSs with frequent exposure to Spanish in their early years. Thomas et al. (2014), who found non monolingual-like performance in the plural constructions of Welsh minority speakers, argue that this long-lasting effect is related to the nature of the linguistic property, which needs a high amount of exposure in the critical years in order to be fully acquired, because of its opacity and complexity.

A sufficient amount of exposure seems to be particularly relevant regarding the phonetic/phonological competence of HSs. Rato et al. (2015) analyze the accent of EP HSs in Germany through foreign accent ratings, an intelligibility and a comprehensibility task, comparing them with monolingual EP speakers and German L2 
learners of EP. The results reveal that overall HSs are perceived as having a monolingual-like EP accent, being clearly differentiated from L2 learners. In a subsequent study, Flores and Rato (2016) applied a more refined rating scale and characterized the speakers by several biographic variables, including their age of onset of acquisition (AoA) of German. A later AoA of German means a more extended period of high exposure to Portuguese in early stages of development. In this case, the results show a significant correlation between the AoA of German and the degree of perceived native accent in Portuguese, i.e., speakers who were born in Germany and grew up with both languages were less frequently rated as having a native Portuguese accent than the speakers who were immersed in the German environment only at ages 2-8. This finding is in line with the results of Kupisch et al. (2014) on Italian-German and French-German 2L1ers, who are not perceived as foreign accented in the majority language, while the degree of perceived foreignness in the HL depends significantly on the amount of contact with this language during childhood.

\section{Type of Input}

Not only quantity of exposure but also quality of exposure, i.e., the type of linguistic input provided by the minority language environment, influences HL development. In some cases, the second- and third-generation speakers are exposed to and acquire a variety that has already undergone some changes and is, thus, no longer identical to the language spoken in the country of origin, at least in some language domains. In Germany, this is likely to be the case of immigrant Turkish spoken within large Turkish communities (Kallmeyer and Keim 2003). For Romance communities this still needs to be systematically investigated by large-scale sociolinguistic studies. The corpus studies conducted so far on Spanish, Italian, and Portuguese immigrant speech (Di Venanzio et al. 2012, 2016; Flores et al. in press, respectively) analyze the spontaneous speech of first-generation immigrants and compare it with speech data of HSs of the same community and monolingual speakers in the country of origin. Results focused on the realization of object pronouns suggest that the speech of firstgeneration migrants does not provide linguistic input that already bears traces of language attrition or change.

Language use within immigrant communities is largely restricted to colloquial, oral registers, which display variation and nonstandard forms or even lack certain linguistic properties. This is accounted for by the Missing Input Competence Divergence Hypothesis, initially proposed by Pires and Rothman (2009), who argue that often HSs show lack of knowledge of certain linguistic structures because these are not in the input they receive. The authors discuss the case of inflected infinitives, which occur mainly in standard Brazilian but not in the colloquial registers that HSs are exposed to. Dominant exposure to colloquial language registers and reduced contact with the standard norm, particularly with formal registers and written sources, is certainly a factor that shapes the linguistic competence of Romance 
HSs in Germany. The Portuguese HSs studied by Rinke and Flores (2014) and Flores and Rinke (2015) exhibit little knowledge of properties of the EP pronoun system that show variation in spoken registers and that need formal schooling in order to be fully mastered also by monolingual children. Furthermore, contact with the standard norm, through contact with various sources of input (e.g., media, school, public administration), constitutes a way of counterweighing linguistic variation present in the vernacular.

\section{The Role of Heritage Language Instruction}

An important source of $\mathrm{HL}$ input is the classroom setting: first, because it is a further source of contact with the HL and adds quantitatively to the contexts where the HL may be used apart from the family; second, because it constitutes a context that provides contact with the standard norm; third, because it enables explicit training of linguistic structures and enhances reading and writing skills. In Germany, HLs are mainly taught in extracurricular HL programs, which take place once or twice a week in the afternoon or on Saturdays. High-quality bilingual education programs, where the HL is an official school language together with German, are rare. Bylund and Díaz (2012) analyzed the effect of HL instruction on HSs language proficiency in similar extracurricular HL classes in Sweden and concluded that these courses have a positive effect on HL proficiency but noted also that these effects are not longlasting. HSs who no longer attend HL classes are outperformed by HSs enrolled in these courses. This suggests that HL classes as an additional context where the HL is spoken foster HL use (see discussion in Di Venanzio et al. 2012) and may promote ethnic identity and positive attitudes toward the culture of origin (Melo-Pfeifer 2015). However, the extracurricular nature of these classes and the reduced course hours are insufficient to promote ample schooling and foster academic competences equal to the literacy skills developed in the majority language.

An example of more successful HL exposure are cases where the HL is not the target of instruction but the medium, as in the case of the HSs studied by Kupisch and colleagues (see Kupisch et al. 2014, for an overview). These speakers attended a French school in Hamburg, Germany. They performed monolingual-like with respect to various morphosyntactic properties and some aspects of pronunciation in both French and German (see also Kupisch and Rothman 2016).

The fact that instruction has a crucial role to play is witnessed by a series of studies by Kupisch and colleagues with simultaneous bilinguals speaking different language combinations, namely German-Italian and German-French. The GermanFrench population attended French schools where French was the medium of instruction while the German-Italian speakers attended German schools and additional HL language classes during their childhood. As adults, the German-French speakers were more monolingual-like in both languages (Kupisch and Rothman 2016). Thus, quality of exposure plays a crucial role. 


\section{Conclusions}

Overall, linguistic research on Romance heritage speakers in Germany reveals the picture of a bilingual population with high proficiency in both dominant environmental language and HL, which often does not differ qualitatively from the native competence of monolingual speakers. This contrasts with the results of many studies on Romance HSs living in the USA (e.g., Montrul and colleagues). The source of the differences observed in both populations may reside in the amount of contact the speakers have with the HL. All studies on Romance HSs in Germany reviewed in this paper document frequent exposure to the HL from birth until adulthood, even if the societal language, German, is more present in the HSs' daily life. Not only language choice within immigrant families, but also geographical and cultural proximity to the countries of origin, along with attendance of HL classes may foster native-like proficiencies (Flores 2015b).

\section{References}

Argyri, E., \& Sorace, A. (2007). Crosslinguistic influence and language dominance in older bilingual children. Bilingualism: Language and Cognition, 10, 77-99.

Berman, R. A. (1979). The (re)emergence of a bilingual: Case-study of a Hebrew-English child. Working Papers in Bilingualism, 19, 157-179.

Bernardini, P., \& Schlyter, S. (2004). Growing syntactic structure and code-mixing in the weaker language: The Ivy Hypothesis. Bilingualism: Language and Cognition, 7(1), 49-70.

Bianchi, G. (2013). Gender in Italian-German bilinguals: A comparison with German L2 learners of Italian. Bilingualism: Language and Cognition, 16(3), 538-557.

Birdsong, D. (2014). Dominance and age in Bilingualism. Applied Linguistics, 35(4), 374-392.

Bohman, T., Bedore, L., Peña, E., Mendez-Perez, A., \& Gillam, R. B. (2010). What you hear and what you say: Language performance in Spanish-English bilinguals. International Journal of Bilingual Education and Bilingualism, 13(3), 325-344.

Bylund, E., \& Díaz, M. (2012). The effects of heritage language instruction on first language proficiency. A psycholinguistic perspective. International Journal of Bilingual Education and Bilingualism, 5, 593-609.

Cantone, K. (2007). Code-switching in bilingual children. Dordrecht: Springer.

Dabrowska, E. (2012). Different speakers, different grammars. Linguistic Approaches to Bilingualism, 2(3), 219-253.

Di Venanzio, L., Schmitz, K., \& Rumpf, A. L. (2012). Objektrealisierungen und -auslassungen bei transitiven Verben im Spanischen von Herkunftssprechern in Deutschland. Linguistische Berichte, 232, 437-461.

Di Venanzio, L., Schmitz, K., \& Rumpf, A. L. (2016). Objects of transitive verbs in Italian as a heritage language in contact with German. Linguistic Approaches to Bilingualism. doi:10.1075/ lab.13041.divissn 1879-9264.

Dunn, A. L., \& Fox Tree, J. E. (2009). A quick, gradient Bilingual dominance scale. Bilingualism: Language and Cognition, 12, 273-289.

Fischer, S., \& Rinke, E. (2013). Explaining the variability of clitic doubling across Romance: A diachronic account. Linguistische Berichte, 236, 255-272.

Flores, C. (2015a). Losing a language in childhood: A longitudinal case study on language attrition. Journal of Child Language, 42(3), 562-590. 
Flores, C. (2015b). Understanding heritage language acquisition. Some contributions from the research on heritage speakers of European Portuguese. Lingua, 164, 251-265.

Flores, C., \& Barbosa, P. (2014). When reduced input leads to delayed acquisition: A study on the acquisition of clitic placement by Portuguese heritage speakers. International Journal of Bilingualism, 18(3), 304-325.

Flores, C., \& Rato, A. (2016). Global accent in the Portuguese speech of heritage returnees. Journal of Heritage Language, 13(2), 161-183.

Flores, C., Rinke, E. (2015). Um estudo comparativo sobre o conhecimento do sistema pronominal português por parte de Falantes de Português Língua de Herança e Falantes de uma Língua Segunda. In MA Marques, X Rei, (Eds.), Novas perspetivas linguísticas no espaço galegoportuguês (Monografia 10, pp. 11-33). Corunha: Universidade da Corunha.

Flores, C., Santos, A. L., Marques, R., \& Jesus, A. (2016). Age and input effects in the acquisition of mood in Heritage Portuguese. Journal of Child Language. doi:10.1017/ S0305000916000222.

Flores, C., Rinke, E., \& Azevedo, C. (in press). Object realization across generations. A closer look on the spontaneous speech of Portuguese first and second generation migrants. In E Domenico (Ed.), Complexity in acquisition. Cambridge: Cambridge Scholars.

Gathercole, V. C. M., \& Thomas, E. M. (2009). Bilingual first-language development: Dominant language takeover, threatened minority language take-up. Bilingualism: Language and Cognition, 12(2), 213-237.

Gawlitzek-Maiwald, I., \& Tracy, R. (1996). Bilingual bootstrapping. Linguistics, 34, 901-926.

Genesee, F. (1989). Early bilingual development: One language or two? Journal of Child Language, 16(1), 161-179.

Genesee, F., Nicoladis, E., \& Paradis, J. (1995). Language differentiation in early bilingual development. Journal of Child Language, 22, 611-631.

Ingram, D. (2002). The measurement of whole-word productions. Journal of Child Language, 29 (4), 713-733.

Kallmeyer, W., \& Keim, I. (2003). Linguistic variation and the construction of social identity in a German-Turkish setting. A case study of an immigrant youth group in Mannheim, Germany. In J. Androutsopoulos \& A. Georgakopoulou (Eds.), Discourse constructions of youth identities (pp. 29-46). Amsterdam/Philadelphia: John Benjamins.

Kehoe, M. (2002). Developing vowel systems as a window to bilingual phonology. International Journal of Bilingualism, 6, 315-334.

Kehoe, M., Trujillo, C., \& Lleó, C. (2001). Bilingual phonological acquisition: An analysis of syllable structure and VOT. In K. Cantone \& M. O. Hinzelin (Eds.), Proceedings of the colloquium on structure, acquisition and change of Grammars: Phonological and syntactic aspects, Arbeiten zur Mehrsprachigkeit 27 (pp. 38-54). Hamburg: Universität Hamburg.

Kehoe, M., Lleó, C., \& Rakow, M. (2004). Voice onset time in bilingual German-Spanish children. Bilingualism: Language and Cognition, 7(1), 71-88.

Kupisch, T. (2007). Determiners in bilingual German-Italian children: What they tell us about the relation between language influence and language dominance. Bilingualism: Language and Cognition, 10(1), 57-78.

Kupisch, T. (2012). Generic subjects in the Italian of early German-Italian bilinguals and German learners of Italian as a second language. Bilingualism: Language and Cognition, 15(4), 736-756.

Kupisch, T. (2014). Adjective placement in simultaneous bilinguals (German-Italian) and the concept of cross-linguistic overcorrection. Bilingualism: Language and Cognition, 17(1), 222-233.

Kupisch, T., Barton, D., Hailer, K., Kostogryz, E., Lein, T., Stangen, I., \& van de Weijer, J. (2014). Foreign accent in adult simultaneous bilinguals. Heritage Language Journal, 11(2), 123-150.

Kupisch T, Klaschik E. Language separation and gender marking in bi-dialectal Italian-Venetian children. Ms, University of Konstanz/the Arctic University of Norway/University of Hamburg; forthcoming. 
Kupisch, T., \& Rothman, J. (2016). Terminology matters! Why difference is not incompleteness and how early child bilinguals are heritage speakers. International Journal of Bilingualism. Online First. doi: $10.1177 / 1367006916654355$.

Kupisch, T., \& van de Weijer, J. (2016). The role of the childhood environment for language dominance: A case study of adult simultaneous bilingual speakers of German and French. In C. Silva Corvalán \& J. Treffers-Daller (Eds.), Language dominance in bilinguals: Issues of measurement and operationalization (pp. 174-194). Cambridge: Cambridge University Press.

Leopold, W. (1949). Speech development of a bilingual child (Volume 4). Evanston: Northwestern University Press.

Lleó, C. (2002). The role of markedness in the acquisition of complex prosodic structures by German-Spanish bilinguals. International Journal of Bilingualism, 6, 291-313.

Lleó, C., \& Rakow, M. (2005). Markedness effects in voiced stop spirantization in bilingual German-Spanish children. In J. Cohen, K. T. McAlister, K. Rolstad, \& J. MacSwan (Eds.), Proceedings of the 4th international symposium on bilingualism (pp. 1353-1371). CD Rom: Cascadilla Press.

Lleó, C., Kuchenbrandt, I., Kehoe, M., \& Trujillo, C. (2003). Syllable final consonants in Spanish and German monolingual and bilingual acquisition. In N. Müller (Ed.), (Non)Vulnerable domains in bilingualism (pp. 191-220). Amsterdam: John Benjamins.

Lloyd-Smith, A., Gyllstad, H., \& Kupisch, T. (2016). Transfer into L3 English. Global accent in German-dominant heritage speakers of Turkish. Linguistic Approaches to Bilingualism. Published online. doi:10.1075/lab.15013.llo.

Meisel, J. (1989). Early differentiation of languages in bilingual children. In K. Hyltenstam, \& L. Obler (Eds.), Bilingualism across the lifespan. Aspects of acquisition, maturity and loss (pp. 13-40). Cambridge: Cambridge University Press.

Melo-Pfeifer, S. (2015). The role of the family in heritage language use and learning: Impact on heritage language policies. International Journal of Bilingual Education and Bilingualism, 18 (1), 26-44.

Montrul, S. (2010). Current issues in heritage language acquisition. Annual Review of Applied Linguistics, 30, 3-23.

Montrul, S., \& Ionin, T. (2010). Transfer effects in the interpretation of definite articles by Spanish heritage speakers. Bilingualism: Language and Cognition, 13(4), 449-473.

Müller, N., \& Hulk, A. (2001). Crosslinguistic influence in bilingual language acquisition: Italian and French as recipient languages. Bilingualism: Language and Cognition, 4, 1-21.

Paradis, J., \& Genesee, F. (1996). Syntactic acquisition in bilingual children: Autonomous or interdependent? Studies in Second Language Acquisition, 18(1), 1-25.

Pires, A., \& Rothman, J. (2009). Disentangling sources of incomplete acquisition: An explanation for competence divergence across heritage grammars. International Journal of Bilingualism, 13 (2), 211-238.

Rato, A., Flores, C., Neves, D., \& Oliveira, D. (2015). A competência fonológica de falantes bilingues luso-alemães: um estudo sobre sotaque global, compreensibilidade e inteligibilidade da sua língua de herança. Diacrítica, 29(1), 297-326.

Rinke, E., \& Flores, C. (2014). Heritage Portuguese bilinguals' morphosyntactic knowledge of clitics. Bilingualism: Language and Cognition, 17(4), 681-699.

Rodina, Y., \& Westergaard, M. (2015). Grammatical gender in bilingual Norwegian-Russian acquisition: The role of input and transparency. Bilingualism: Language and Cognition. doi: $10.1017 / \mathrm{S} 1366728915000668$.

Santos, A. L., \& Flores, C. (2016). Comparing heritage speakers and late L2-learners of European Portuguese: Verb movement, VP ellipsis and adverb placement. Linguistic Approaches to Bilingualism, 6(3), 308-340.

Schlyter, S. (1994). Early morphology in French as the weaker language in Swedish French. Scandinavian Working Papers in Bilingualism, 9, 67-87.

Schmitz, K., di Venanzio, L., \& Scherger, A. L. (2016). Null and overt subjects in Italian and Spanish heritage speakers in Germany. Lingua. doi:10.1016/j.lingua.2016.04.004. 
Serratrice, L., Sorace, A., Filiaci, F., \& Baldo, M. (2009). Bilingual children's sensitivity to specificity and genericity: Evidence from metalinguistic awareness. Bilingualism: Language and Cognition, 12, 239-257.

Stöhr, A., Akpinar, D., Bianchi, G., \& Kupisch, T. (2012). Gender marking in Italian-German heritage speakers and L2-learners of German. In K. Braunmueller \& C. Gabriel (Eds.), Multilingual individuals and multilingual societies (MIMS) (pp. 153-170). Amsterdam: John Benjamins.

Suchtelen, P. (2014). Maintained and acquired heritage Spanish in the Netherlands: The case of dative constructions. Applied Linguistics Review, 5(2), 375-400.

Thomas, E. M., Williams, N., Jones, L., Davies, S., \& Binks, H. (2014). Acquiring complex structures under minority language conditions: Bilingual acquisition of plural morphology in Welsh. Bilingualism: Language and Cognition, 17(3), 478-494.

Unsworth, S. (2013). Assessing the role of current and cumulative exposure in simultaneous bilingual acquisition: The case of Dutch gender. Bilingualism: Language and Cognition, 16 (1), 86-110.

Unsworth, S. (2015). Quantity and quality of language input in bilingual language development. In E. Nicoladis \& S. Montanari (Eds.), Lifespan perspectives on bilingualism (pp. 136-196). Berlin: Mouton de Gruyter.

Volterra, V., \& Taeschner, T. (1978). The acquisition and development of language by bilingual children. Journal of Child Language, 5, 311-326.

Yip, V., \& Matthews, S. (2000). Syntactic transfer in a Cantonese-English bilingual child. Bilingualism: Language and Cognition, 3, 193-207.

Yip, V., \& Matthews, S. (2006). Assessing language dominance in bilingual acquisition: A case for mean length utterance differentials. Language Assessment Quarterly, 3(2), 97-116. 